\title{
Fracture Properties of Multipass Submerged Arc Weld of HSLA Steel Produced by Using Flux Cored Filler Wire
}

\author{
P. K. GHOSH, P. K. SINGH and N. B. POTLURI
}

Welding Research Laboratory, Department of Mechanical and Industrial Engineering, University of Roorkee, Roorkee247667, India.

(Received on June 17, 1998; accepted in final form on August 20, 1998)

\begin{abstract}
Multi pass submerged arc welding of $25 \mathrm{~mm}$ thick structural steel plates has been carried out at different energy input using flux cored filler wire and basic agglomerated flux resulting the weld deposit having chemical composition confirming that of a high strength low alloy (HSLA) steel. Microstructure and hardness of different microstructural regions of the multipass weld has been studied. Tensile properties of the weld deposit has been found out by carrying out tensile test of the weld joint being fractured from the weld. Fracture toughness $\left(K_{0}\right)$ and fatigue crack growth properties of the weld are studied and correlated with the welding energy input, microstructure and ultimate tensile strength of the weld. The increase in energy input has been found to reduce the hardness, ultimate tensile strength and yield strength, but to enhance the ductility and $K_{Q}$ of the weld primarily due to its influence on microstructure of the weld deposit. However, the increase in energy input has been found to reduce the $d a / d N$ at higher $\Delta K$ but, it has been found to enhance the same at lower $\Delta K$. The $K_{\mathrm{Q}}$ and $d a / d N$ of the weld are found to be well correlated with its tensile strength, where an increase in tensile strength reduces the $K_{Q}$ but enhances the $d a / d N$ at $\Delta K$ higher than $30 \mathrm{MPa} \sqrt{\mathrm{m}}$.
\end{abstract}

KEY WORDS: submerged arc welding; flux cored filler wire; HSLA steel weld deposit; multipass weld; energy input; weld characteristics; microstructure; hardness; tensile properties; fatigue crack growth rate; fracture toughness $\left(K_{0}\right)$.

\section{Introduction}

The high strength low alloy (HSLA) steels have become widely popular in fabrication of various structures in many critical and non critical applications due to high economy and more allowable design stresses permitted by their significantly enhanced yield strength. The fabrication of these structures largely involves different welding processes, where the multipass submerged arc welding (SAW) is commonly used during joining of thick steel sections. A successful and economical use of HSLA steel weld very much depend on proper selection of welding consumable and possibility of using high heat input welding process allowing high deposition rate. ${ }^{1-3)}$ The SAW process has been successfully applied in many occasions of multipass welding of thick steel plates, where the weld properties are significantly governed by the microstructure of weld deposit. ${ }^{2-7)}$ Thus, to enhance the range of heat input of the SAW process in producing the multipass weld of HSLA steel a characterisation of weld properties with respect to its microstructure and energy input of the process at different welding parameters is very much necessary. This is because the failure of welded structures is often found to be initiated from the weld metal and fracture properties of a weld significantly depend on morphology of the weld deposit, ${ }^{7,8)}$ which in multipass weld is primarily characterised by the proportion of the dendritic and reheat refined regions ${ }^{9)}$ present in it. The morphology of a multipass weld is largely governed by the weld thermal cycle and characteristics of deposition dictated by the energy input and welding parameters of the process. ${ }^{9 !}$ Further the characteristics of deposition also varies significantly with the type of welding electrode, such as a solid or flux cored electrode, used in a welding process. In recent years the use of flux cored electrode as filler wire is very much favoured by many industries primarily due to its ability to produce good quality weld of a desired chemical composition with high deposition rate. But, hardly any work has been reported so far on the various aspects, as discussed above, of a multipass submerged arc weld produced by using flux cored filler wire.

By keeping a pace with the modern concepts of structural design and economy the growing interest and awareness about the safety and reliability of a welded structure, especially under dynamic loading, has made it imperative to understand the fracture mechanics behaviour of a weld ${ }^{10)}$ along with its conventional mechanical properties. But a very limited number of literature is available so far on fracture mechanics 
Table 1. Chemical composition of the filler wire. (wt \%)

\begin{tabular}{cccccc}
$\mathrm{C}$ & $\mathrm{Mn}$ & $\mathrm{Si}$ & $\mathrm{Cr}$ & $\mathrm{Ni}$ & $\mathrm{Mo}$ \\
\hline 0.08 & 1.5 & 0.35 & 0.8 & 2.5 & 0.4 \\
\hline
\end{tabular}

Table 2. Chemical composition of the basic agglomerated flux. $(w t \%)$

\begin{tabular}{ccccc}
\hline $\mathrm{SiO}_{2}+\mathrm{TiO}_{2}$ & $\mathrm{CaO}+\mathrm{MgO}$ & $\mathrm{Al}_{2} \mathrm{O}_{3}+\mathrm{MnO}$ & $\mathrm{CaF}_{2}$ & Basicity index \\
\hline 15 & 40 & 20 & 25 & 3.1 \\
\hline
\end{tabular}

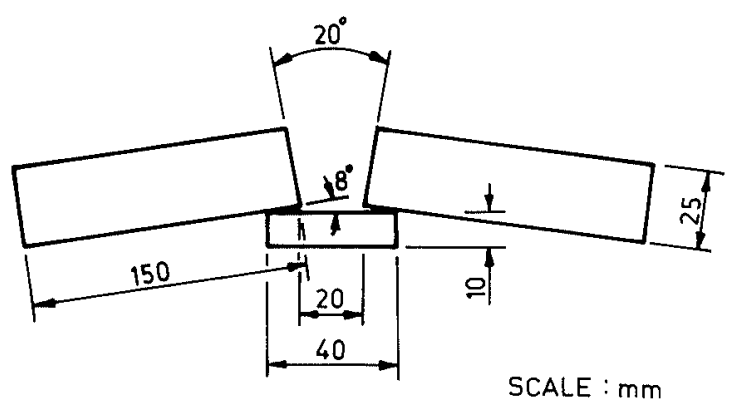

Fig. 1. Schematic diagram of the weld groove.

behaviour of a multipass weld and its correlation with the microstructure, weld thermal cycle and welding parameters. In this investigation an effort has been made to study the effect of energy input of welding, varied with a change in welding parameters, on microstructure, fatigue crack growth rate and fracture toughness of multipass weld, deposited by submerged arc welding process using flux cored steel wire electrode of a high strength low alloy steel.

\section{Experimental}

\subsection{Welding}

Submerged arc welding of structural steel plates of dimension $400 \times 150 \times 25 \mathrm{~mm}$ was carried out using $3.2 \mathrm{~mm}$ diameter flux cored filler wire and basic agglomerated flux. Chemical compositions of the filler wire and agglomerated flux are shown in Tables 1 and 2 respectively. The chemical composition of the filler wire deposit weld metal confirming the composition of a HSLA steel. To minimise final distortion of the weld, the base plate and the backing plate was tack welded with a pre-bend angle of $8^{\circ}$ using manual metal arc welding process. The welding was carried out by multipass deposition in a groove having a backing plate of dimension $430 \times 40 \times 10 \mathrm{~mm}$ as schematically shown in Fig. 1. Prior to welding the groove surface and its adjacent region of the base plate was thoroughly cleaned mechanically and by applying acetone to remove the presence of rust or any oil and grease on the faying surface. During welding the energy input was varied by changing the welding current and speed as shown in Table 3, when the electrode polarity was maintained as direct current electrode positive (DCEP).

After welding the run on and run off portions of the weld was discarded and the specimens for metallography,
Table 3. Welding parameters.

\begin{tabular}{cccc}
\hline $\begin{array}{c}\text { Welding current } \\
(\mathrm{A})\end{array}$ & $\begin{array}{c}\text { Arc voltage } \\
(\mathrm{V})\end{array}$ & $\begin{array}{c}\text { Welding speed } \\
(\mathrm{cm} / \mathrm{min})\end{array}$ & $\begin{array}{c}\text { Energy input } \\
(\mathrm{kJ} / \mathrm{mm})\end{array}$ \\
\hline 400 & 28 & 40 & 1.68 \\
450 & 28 & 40 & 1.89 \\
500 & 28 & 40 & 2.1 \\
450 & 28 & 30 & 2.52 \\
450 & 28 & 35 & 2.16 \\
\hline
\end{tabular}

tensile testing, fatigue crack growth rate testing and fracture toughness testing, were collected by saw cutting from the stable welding region of the joint.

\subsection{Chemical Analysis and Metallography}

The chemical composition of weld deposit was analysed under atomic absorption spectrometer and infrared carbon-sulphur analyser using the chips drilled out from it. Transverse section of the weld was prepared and polished by standard metallographic procedure and etched in $5 \%$ alcoholic nitric acid (nital) solution to reveal the microstructure of weld deposit for studying under optical microscope.

\subsection{Hardness Test}

Hardness measurement of the weld was carried out by Vicker's diamond indentation along the weld centreline, at a load of $10 \mathrm{~kg}$, as revealed on the transverse section of weld joint prepared for the metallographic studies. The hardness of various microstructural regions such as the coarse and fine dendritic regions and the coarse and fine grain regions of the weld was also studied by Vicker's microhardness indentation at a load of $200 \mathrm{~g}$.

\subsection{Tensile Test}

Tensile properties of the weld joint, such as its ultimate tensile strength $\left(\sigma_{u}\right)$, yield strength $\left(\sigma_{y \mathrm{~s}}\right)$ and elongation, were studied using standard (ASTM E8M-89b) round tensile specimen having weld at its centre as schematically shown in Fig. 2. The test was carried out in a universal testing machine operated at a cross head speed of $1 \mathrm{~mm} / \mathrm{min}$. Elongation of the specimen was studied at a gauge length of $40 \mathrm{~mm}$ with the weld at its centre and the yield strength was determined at $0.2 \%$ off-set strain on the stress-strain diagram.

\subsection{Fatigue Crack Growth Rate Test}

Fatigue crack growth characteristics of the weld metal was studied using $15 \mathrm{~mm}$ thick $\mathrm{C}(\mathrm{T})$ specimen, which was precision machined from the weld in accordance with the ASTM E647-88a by keeping the orientation of notch along the direction of welding. A schematic diagram of the $\mathrm{C}(\mathrm{T})$ specimen has been shown in Fig. 3. The test was carried out on pre-cracked specimen. The initial crack length to width ratio $\left(a_{0} / W\right)$ of the specimen was kept as 0.25 . During pre-cracking under dynamic loading the ratio of crack length $(a)$ to width of the specimen $(W)$ was kept in the range of 0.3-0.32 using compliance method of crack length measurement, where the stress intensity factor $(K)$ was maintained constant by reducing the maximum load under load control mode of the machine.

The fatigue crack growth (FCG) tests were performed 


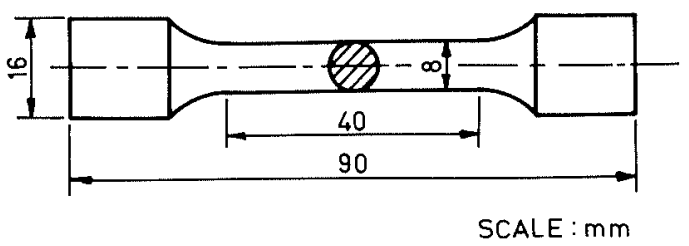

Fig. 2. Schematic diagram of the tensile specimen.
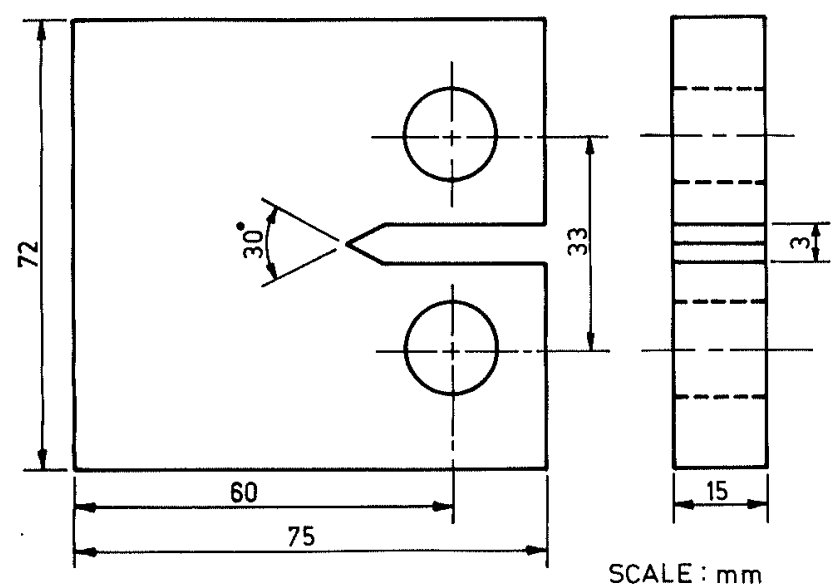

SCALE : mm

Fig. 3. Schematic diagram of the $C(T)$ specimen.

under cyclic loading in accordance with the procedure outlined in ASTM E647-88a using fully automated close loop servo-hydraulic universal testing machine. The test was carried out in open air laboratory environment at room temperature and using a sinusoidal wave form having cyclic frequency of $15 \mathrm{~Hz}$. The test was carried out by constant amplitude method at a given minimum to maximum stress ratio $(R)$ of 0.1 , where the minimum and maximum stress intensity enhanced with the increase of crack length. Here also the compliance method was adopted for measurement of crack length, where the $K$ value was determined from the correlation of load and crack length at a given stress intensity. All the tests were conducted under load control mode of operation of the machine with a load control card range being selected based on specimen thickness, thereby minimising any error arising from load control. A MTS based computer software was used to conduct the test and store the test results of (i) cycle number, $N$, (ii) maximum load, (iii) minimum load and (iv) crack length. The software was capable to calculate the crack length based on CMOD gauge displacement and to adjust automatically the minimum and maximum load. A fifth order compliance polynomial was used to correlate the ratio of change in crack opening displacement (COD) to change in load with the crack aspect ratio $(a / W)$ to determine the crack length $a$. A visual crack length measurement was also periodically carried out to ensure that the curvature of the crack length is within acceptable limits. The crack length along with the corresponding minimum and maximum load and cyclic counts $(N)$ were saved in data file at certain interval. The tabulated data was used for evaluation of crack growth rate $(d a / d N)$ and the stress intensity factor range $(\Delta K)$. The fatigue crack growth characteristics of the weld metal deposited at different energy input was plotted as $\log (d a / d N)$ vs. $\log \Delta K$ and analysed in the light of the Paris law.

$$
(d a / d N)=C(\Delta K)^{m}
$$

where $C$ and $m$ are the material constants. The constants $C$ and $m$ for a crack growth rate were determined by fitting the data points to the power law curve (Eq. (1)) using standard software of linear regression analysis.

\subsection{Fracture Toughness Test}

The fracture toughness of the weld metal was also studied using $\mathrm{C}(\mathrm{T})$ specimen (Fig. 3), having notch orientation along the direction of welding. The specimens were machined as per the specification of ASTM E399-83. The test was carried out also by confirming the standard test method in accordance to ASTM E399-83 using fatigue pre-cracked specimen, having crack length $a / W=$ 0.5 , under a fully automated closed loop servo-hydraulic testing machine. The maximum load at the end of the pre-cracking was $12.5 \mathrm{kN}$. A MTS based computer software was used to conduct the test and store the test results of load vs. displacement across the notch. The load $P_{\mathrm{Q}}$ corresponding to the $5 \%$ apparent increment of the crack extension was established by drawing a secant line at a specified deviation from the linear portion of the record. The crack length was measured after fracture of the specimens to the nearest of $0.5 \%$ at the three points such as at the centre of the crack front, midway between the centre of the crack front and end of the crack front on fracture surface of the specimen. An average of this three measurements of crack length and the load $P_{\mathrm{Q}}$ were used for evaluation of the plain-strain fracture toughness $K_{\mathrm{Q}}$ as follows.

$$
K_{\mathrm{Q}}=\left(P_{\mathrm{Q}} / B W^{1 / 2}\right) \cdot f(a / W)
$$

where

$$
\begin{aligned}
f(a / W)= & {\left[( 2 + a / W ) \left\{0.866+4.64 a / W-13.32(a / W)^{2}\right.\right.} \\
& \left.\left.+14.72(a / W)^{3}-5.6(a / W)^{4}\right\}\right] /[1-(a / W)]^{3 / 2} \\
P_{\mathrm{Q}}= & \text { Load }(\mathrm{kN}) \\
B= & \text { Specimen thickness }(\mathrm{cm}) \\
W= & \text { Specimen width }(\mathrm{cm}) \\
a= & \text { Crack length }(\mathrm{cm})
\end{aligned}
$$

The evaluated $K_{\mathrm{Q}}$ was verified for valid $K_{\mathrm{IC}}$ by estimating $B$ or $a \geq 2.5\left(K_{\mathrm{Q}} / \sigma_{\mathrm{YS}}\right)^{2}$, where $\sigma_{\mathrm{YS}}$ is $0.2 \%$ off-set yield strength of the weld deposit. It was observed that the $K_{\mathrm{Q}}$ is not equal to $K_{\mathrm{IC}}$ as it does not fulfil the condition of thickness requirement of the specimen, which is used as less than the minimum thickness required for obtaining a valid $K_{\mathrm{IC}}$. Thus, the fracture toughness properties of the weld has been studied in terms of the $K_{\mathrm{Q}}$.

\section{Results and Discussion}

\subsection{Chemical Composition of the Weld}

Chemical composition of the weld metal deposited at different energy input, varied with a change in welding current and speed, has been shown in Table 4. The table depicts that the weld metal confirms the chemical composition of a HSLA steel and the change in welding energy input is having insignificant influence on chemi- 
Table 4. Chemical composition of the weld deposit.

\begin{tabular}{cccccccccc}
\hline $\begin{array}{c}\text { Welding condition } \\
\text { Energy input }(\mathrm{kJ} / \mathrm{mm})\end{array}$ & \multicolumn{8}{c}{ Chemical composition (wt \%) } \\
& $\mathrm{C}$ & $\mathrm{Mn}$ & $\mathrm{Si}$ & $\mathrm{Cr}$ & $\mathrm{Ni}$ & $\mathrm{Mo}$ & $\mathrm{P}$ & $\mathrm{S}$ \\
\hline 1.68 & 0.13 & 1.75 & 0.34 & 0.97 & 2.03 & 0.48 & 0.016 & 0.005 \\
1.89 & 0.13 & 1.80 & 0.35 & 0.95 & 1.98 & 0.48 & 0.019 & 0.006 \\
2.1 & 0.13 & 1.70 & 0.33 & 0.90 & 1.93 & 0.45 & 0.015 & 0.006 \\
2.16 & 0.13 & 1.80 & 0.35 & 0.95 & 1.98 & 0.48 & 0.019 & 0.005 \\
2.52 & 0.12 & 1.86 & 0.36 & 0.96 & 2.06 & 0.49 & 0.017 & 0.005 \\
\hline
\end{tabular}

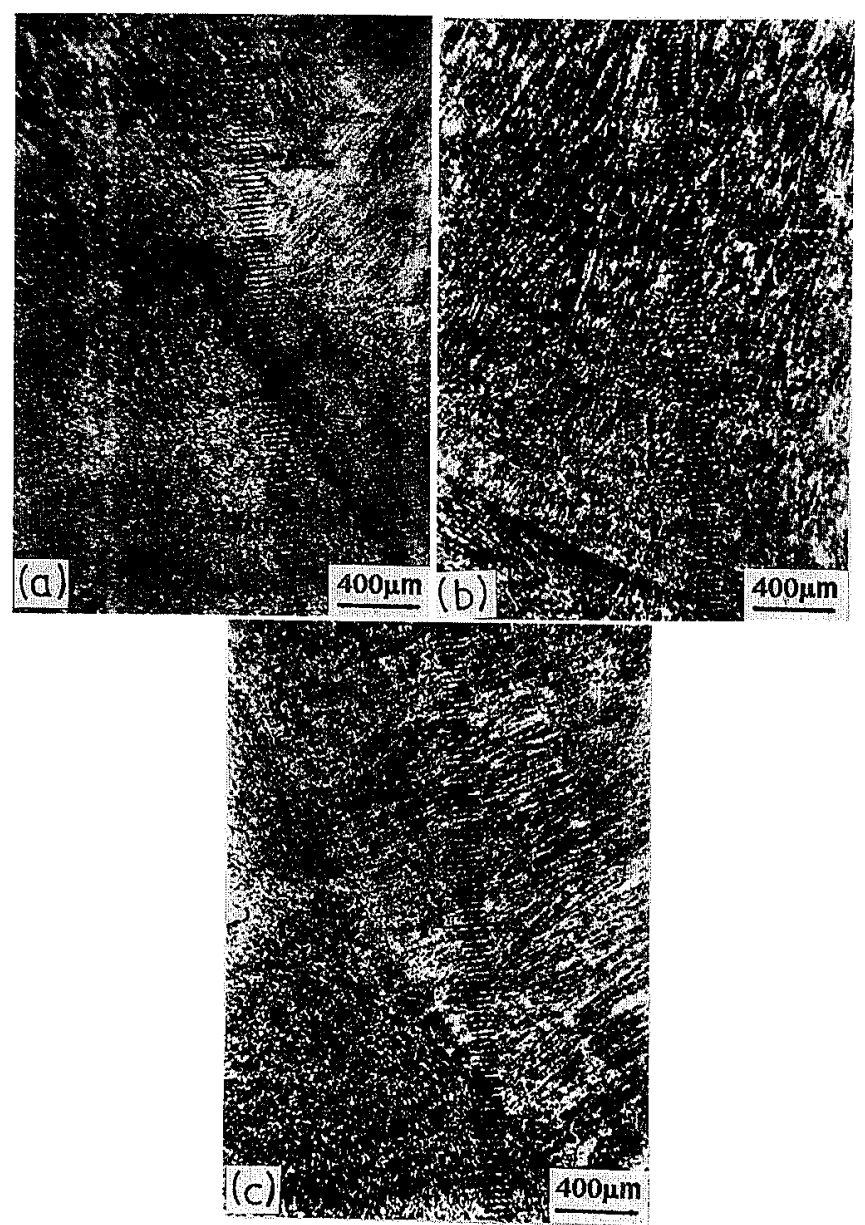

Fig. 4. Microstructure of the multipass weld deposited at different energy input of (a) $1.68 \mathrm{~kJ} / \mathrm{mm}$, (b) $1.89 \mathrm{~kJ} / \mathrm{mm}$ and (c) $2.1 \mathrm{~kJ} / \mathrm{mm}$, caused by the variation in welding current at a given welding speed and are voltage as mentioned in Table 3 .

cal composition of the weld. This is because the small amount of dilution of base material through the weld beads deposited at the groove surface becomes practically negligible to create an appreciable variation in chemical composition of a comparatively large mass of the multipass weld.

\subsection{Microstructure of the Weld}

Microstructure of the welds prepared at different energy input of $1.68,1.89$ and $2.1 \mathrm{~kJ} / \mathrm{mm}$, resulting from a change in welding current to 400,450 and $500 \mathrm{~A}$ respectively at a given welding speed of $40 \mathrm{~cm} / \mathrm{min}$, has been shown in Figs. 4(a), $\mathbf{4 ( b )}$ and $\mathbf{4 ( c )}$ respectively. Similarly at different energy input of 2.16 and 2.52

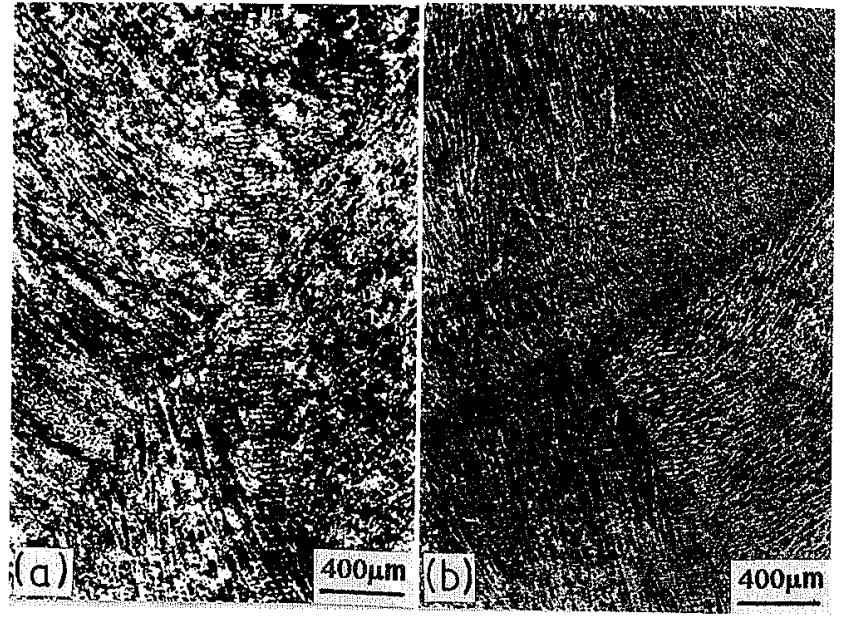

Fig. 5. Microstructure of the multipass weld deposited at diflerent energy input of (a) $2.16 \mathrm{~kJ} / \mathrm{mm}$ and (b) $2.52 \mathrm{~kJ} / \mathrm{mm}$, caused by the variation in welding speed at a given welding current and arc voltage as mentioned in Table 3.

$\mathrm{kJ} / \mathrm{mm}$, varied with a change in welding speed to 30 and $35 \mathrm{~cm} / \mathrm{min}$ at a given welding current of $450 \mathrm{~A}$, the microstructure of the weld has been shown in Figs. 5(a) and $\mathbf{5}(\mathbf{b})$ respectively. The micrographs presented in Figs. 4 and 5 clearly reveal the presence of different microstructural regions consist of coarse dendrite (CD) region, fine dendrite (FD) region, coarse grain reheat (CGR) region and fine grain reheat (FGR) region in the matrix, which is commonly known morphology of a multipass weld. ${ }^{9}$ The typical morphology of these regions are more clearly revealed in the micrographs of higher magnification as presented in Fig. 6. The micrographs shown in Figs. 4 and 5 also depict that the variation in energy input changes the morphology and amount of different microstructural regions in the matrix. In general it is qualitatively marked that the increase in energy input enhances the amount of dendrite along with comparative coarsening of its morphology. This has happened because the variation in welding current and speed changes the geometry of weld bead and weld thermal cycle which significantly affects the morphology and extent of the dendritic and reheat refined regions in the matrix. ${ }^{9)}$

\subsection{Hardness of the Weld}

Hardness ( $\mathrm{HV} \mathrm{10)} \mathrm{of} \mathrm{the} \mathrm{weld} \mathrm{has} \mathrm{been} \mathrm{found} \mathrm{to} \mathrm{be}$ reduced almost lineally with the increase of energy input as shown in Fig. 7. However, the hardness of a 


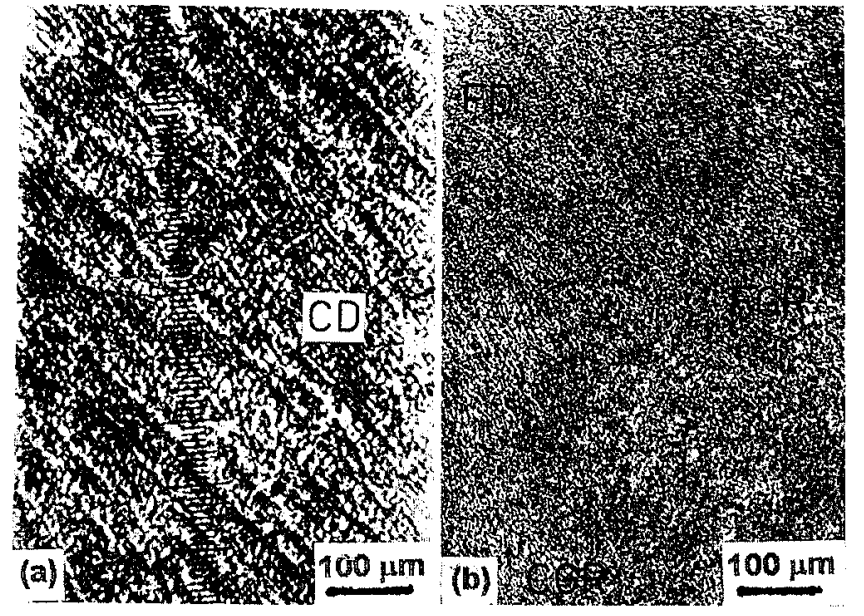

Fig. 6. Morphology of different microstructural regions of the multipass weld revealed at a comparatively higher magnification; Coarse dendrite (CD); Fine dendrite (FD); Coarse grain reheat (CGR) and Fine grain reheat (FGR).

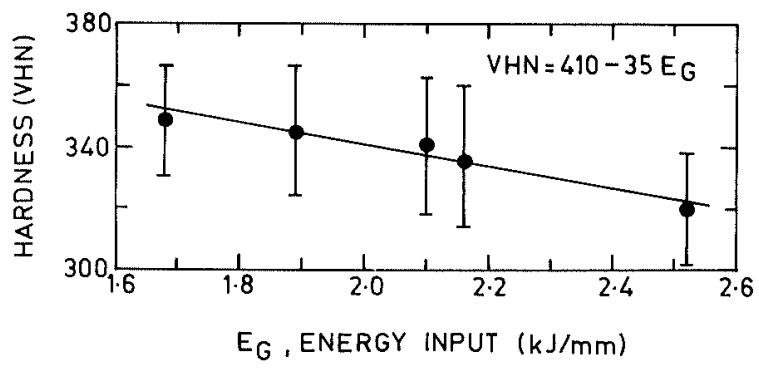

Fig. 7. Effect of energy input on hardness of the weld.

multipass weld is primarily governed by the microhardness of different microstructural regions, as stated earlier, and their proportionate amount in the matrix. The proportion of different microstructural regions in a multipass weld varies with the welding parameters governing the thermal cycle and geometry of weld deposit. ${ }^{9)}$ The microhardness of different microstructural regions has also been found to be reduced logarithmically with the increase of energy input (Fig. 8) causing a gross reduction in hardness of the weld as depicted in Fig. 7. It is also observed in Fig. 8, that at a given energy input the fine dendrite (FD) region of the matrix possesses highest hardness followed by a reduction in hardness of other microstructural regions in order of fine grain reheat (FGR) region, coarse dendrite (CD) region and coarse grain reheat (CGR) region. The difference in nature of variation in hardness ( $\mathrm{HV} \mathrm{10)}$ of the weld with the energy input in reference to that observed in case of microhardness of various microstructural regions of the weld possibly primarily attributed to the presence of all kinds of microstructural regions in the matrix at different proportion at different energy input.

\subsection{Tensile Properties of the Weld Joint}

The effect of energy input on tensile properties of the weld joint has been shown in Fig. 9. During tensile test the specimens are found to fracture from the weld and thus the properties measured by the tensile test primarily represent the tensile properties of weld deposit. In

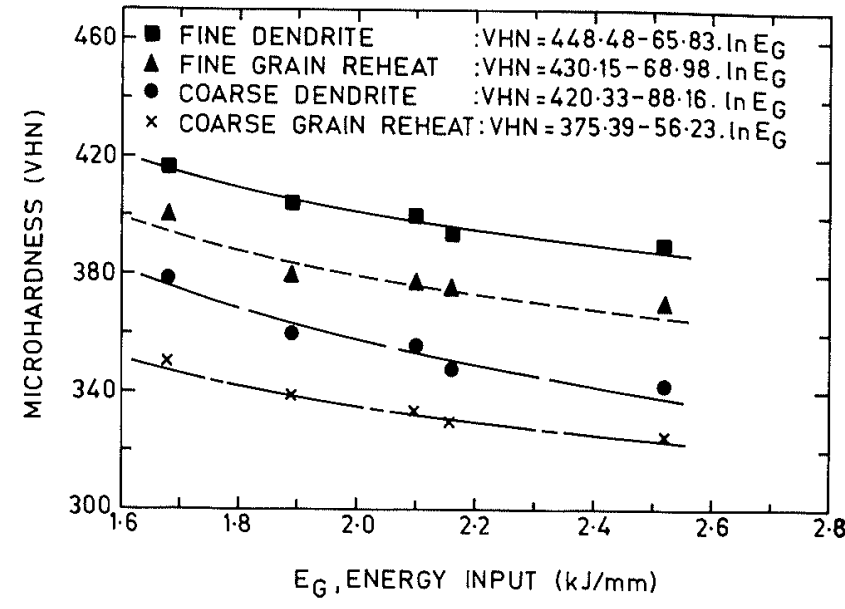

Fig. 8. Effect of energy input on microhardness of different microstructural regions of the weld.

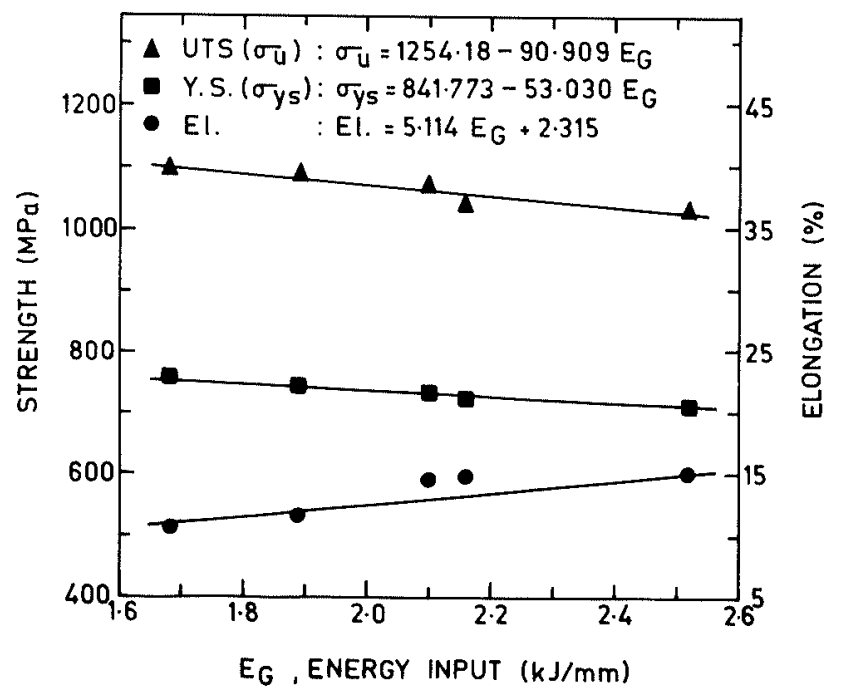

Fig. 9. Effect of energy input on ultimate tensile strength, yield strength and elongation of the weld.

agreement to some earlier observations, ${ }^{1-13)}$ the figure shows that the increase in energy input comparatively reduces the ultimate tensile strength and yield strength but enhances the elongation of the weld. This may be primarily attributed to enhancement in amount of dendrite as well as coarsening of its morphology $9,14-16$ ) with the increase in energy input, as discussed above. The increase in coarse dendrite content of the matrix with the increase of energy input makes it comparatively softer (Figs. 7 and 8) and consequently weaker in agreement to the observations revealed in Fig. 9.

\subsection{Fatigue Crack Growth Properties of the Weld}

The fatigue crack growth rate characteristics of the welds deposited at different energy input has been compared as shown in Fig. 10. The figure depicts that the rate of increase of the fatigue crack growth rate $(d a / d N)$ with the enhancement of stress intensity factor range $(\Delta K)$ significantly reduces with the increase of energy input. The figure also shows that at a given stress intensity factor range the increase in energy input markedly enhances the fatigue crack growth rate especially at the lower range of $\Delta K$ of the order of about 


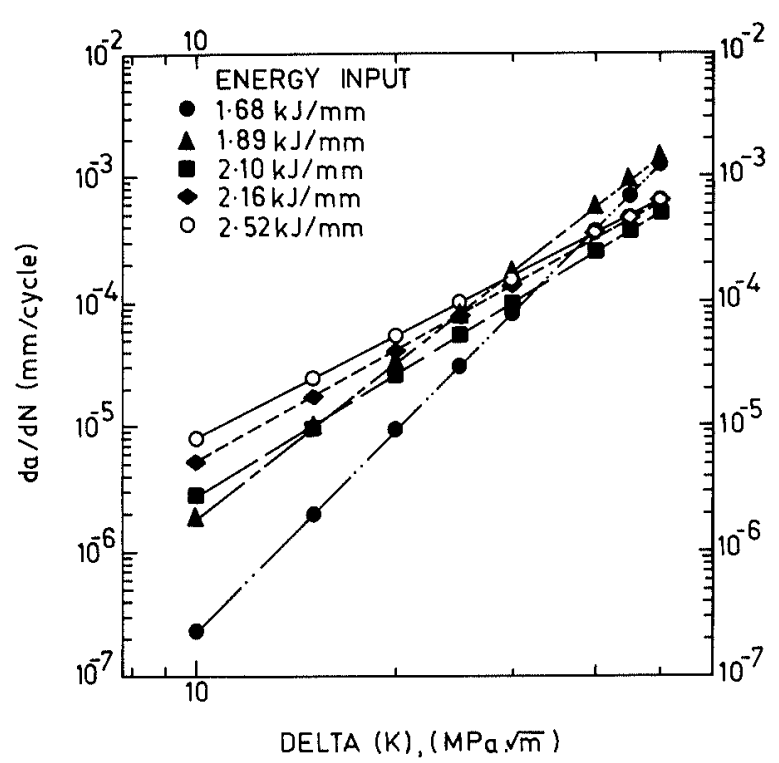

Fig. 10. The relationship of fatigue crack growth rate with stress intensity factor range for the weld prepared at different energy input.

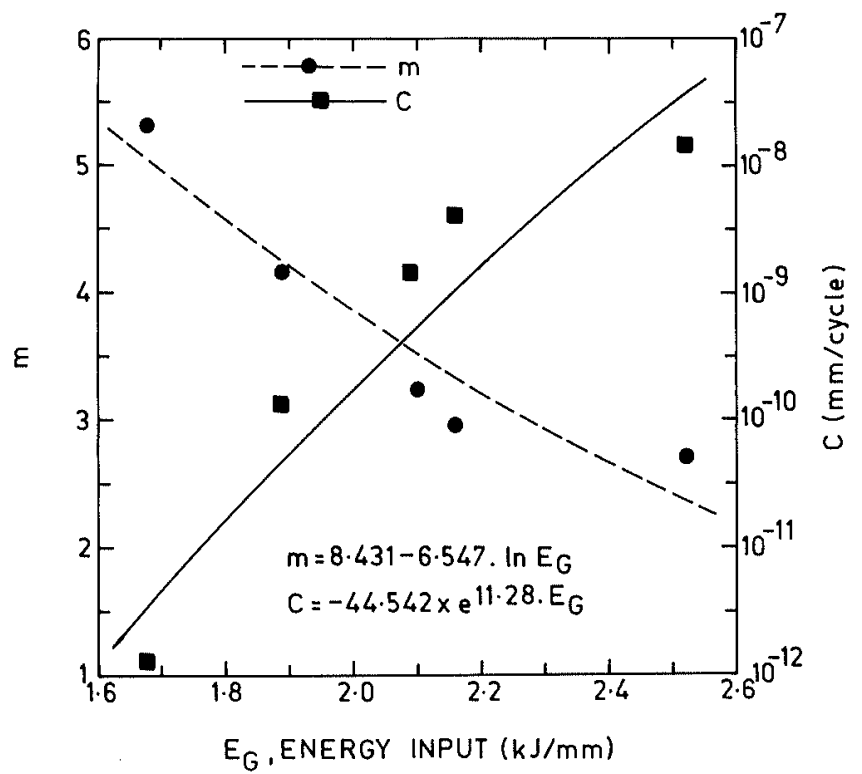

Fig. 11. Effect of energy input on growth exponent $m$ and constant $C$ of the Paris law of fatigue crack growth rate of the weld.

10-30 MPa $\sqrt{\mathrm{m}}$. These behaviours of the $(d a / d N)$ vs. $\Delta K$ relationships with a change in energy input are further corroborated by the logarithmic decrease of $m$ and exponential increase of $C$, of their Paris law relationships, with the increase of energy input as revealed in Fig. 11. At a given $\Delta K$ the influence of energy input on fatigue crack growth rate characteristics of the weld, has been shown in Fig. 12. The figure shows that at a given $\Delta K$ of 15 and $30 \mathrm{MPa} \sqrt{\mathrm{m}}$ the crack growth rate enhances with the increase of energy input but, the rate of increase in crack growth rate reduces with the enhancement of $\Delta K$. However, at a further higher $\Delta K$ of $45 \mathrm{MPa} \sqrt{\mathrm{m}}$ the crack growth rate has been found to be lowered significantly with the increase of energy input.

Fatigue crack growth rate characteristic of a metal largely depends upon its tensile properties. ${ }^{14)}$ The increase

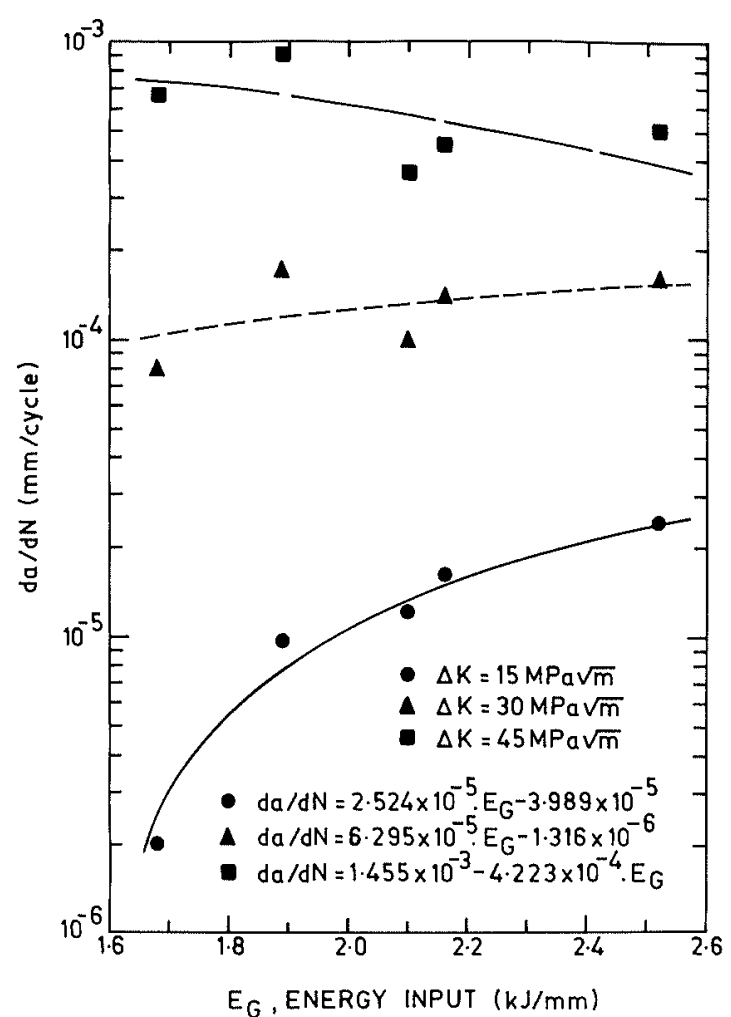

Fig. 12. At a given stress intensity factor range the effect of energy input on fatigue crack growth rate of the weld.

in energy input has been found to reduce tensile strength but to enhance ductility of the weld and thus, it reduces the Paris law exponent $m$ of the crack growth rate with respect to $\Delta K$ as shown in Fig. 11. With the decrease of energy input the increase in tensile strength of the weld primarily resulted the significant increase of crack growth rate in it, especially at the high $\Delta K$ of the order of $45 \mathrm{MPa} \sqrt{\mathrm{m}}$, as shown in Fig. 13. The noted influence of tensile strength on the crack growth rate also confirm the earlier observation. ${ }^{14)}$ However, the effect of tensile strength on enhancement of crack growth rate in the weld has been found to be more strongly of opposite nature, of decrease in crack growth rate with the increase of tensile strength, as one goes on lowering the $\Delta K$ to $30 \mathrm{MPa} \sqrt{\mathrm{m}}$ and $\Delta K$ of $15 \mathrm{MPa} \sqrt{\mathrm{m}}$, as depicted also in Fig. 13. These behaviours of crack growth rate with the change in $\Delta K$ may be primarily attributed to some microscopic features of the matrix affecting the fracture mechanics. These microscopic features may be primarily identified as the extent of formation of cleavage facets and/or initiation, growth and coalescence of micro-void in the matrix under various test conditions. ${ }^{14,17)}$ At a lower $\Delta K$ of the order of $15 \mathrm{MPa} \sqrt{\mathrm{m}}$ the appearance of cleavage like facets in the matrix largely dominates the fracture mechanism, the extent of which reduces with strengthening of matrix by the increase of tensile strength. Thus, at a lower $\Delta K$ the increase in tensile strength reduces the fatigue crack growth rate significantly. But, at higher $\Delta K$ of the order of $45 \mathrm{MPa} \sqrt{\mathrm{m}}$ the microvoid coalescence causing the plastic blunting of the crack tip possibly primarily controls the fatigue crack growth rate, which occurs comparatively more at higher tensile strength of the weld causing an increase in fatigue crack 


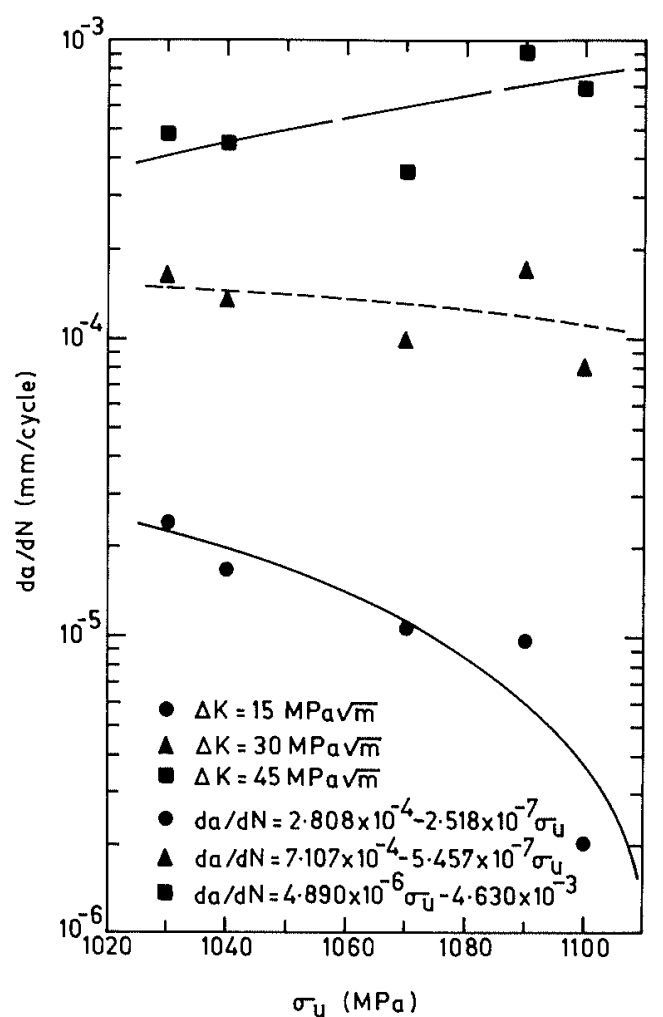

Fig. 13. At a given stress intensity factor range the effect of ultimate tensile strength on fatigue crack growth rate of the weld.

growth rate. ${ }^{17)}$ The fracture mechanism at $\Delta K$ of the order of $30 \mathrm{MPa} \sqrt{\mathrm{m}}$ possibly lies in the transition region of both the mechanisms reversibly affecting the fatigue crack growth rate and thus became practically independent of tensile strength of the weld.

In this context it may be noted that, although the rate of fatigue crack propagation is largely a function of micro level features of the matrix, but in the present case of characterisation of fatigue crack growth properties of the multipass weld it was found appropriate to correlate it with the broad based qualitative microstructural features of the weld, affecting its tensile strength, because of highly heterogeneous nature of distribution of FD, CD, FGR and CGR regions in respect to the crack path in the matrix. However, the comparative influence of the microstructure and tensile strength of the weld on the overall rate of propagation of the fatigue crack in it may be studied by quantitative analysis of the microstructural features of the weld, which was beyond the scope of the present investigation.

Besides all the aspects discussed above the presence of residual stresses in weld deposit also affects the behaviour of fatigue crack propagation by modification of stress field at the crack tip. But, in the present studies on fatigue crack growth characteristics of the weld the role of residual stresses has not been considered because the residual stresses in the interior layers of multipass welds are generally released significantly by thermomechanical processes. ${ }^{18)}$

\subsection{Fracture Toughness of the Weld}

The effect of energy input on plain-strain fracture

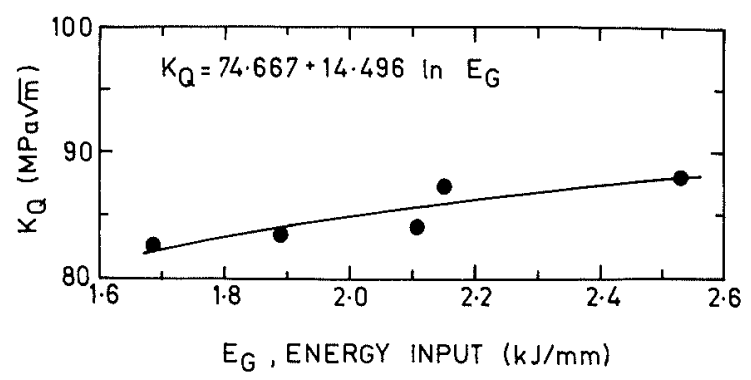

Fig. 14. Effect of energy input on fracture toughness of the weld.

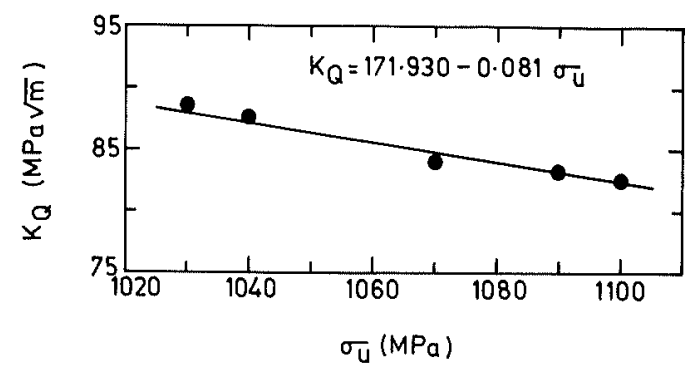

Fig. 15. Effect of ultimate tensile strength on fracture toughness of the weld.

toughness $\left(K_{\mathrm{Q}}\right)$ of the weld has been shown in Fig. 14 . The figure shows that the increase in energy input of the order of $0.84 \mathrm{~kJ} / \mathrm{mm}$ relatively enhances the fracture toughness of the weld by about $6 \mathrm{MPa} \sqrt{\mathrm{m}}$. The enhancement of fracture toughness with energy input is primarily caused by the decrease in tensile strength of the weld as revealed in Fig. 15. The figure depicts that the increase of fracture toughness of the weld by this amount of about $6 \mathrm{MPa} \sqrt{\mathrm{m}}$ is caused by a decrease in its $\sigma_{u}$ of the order of $70 \mathrm{MPa}$. This behaviour is in agreement to an earlier observation ${ }^{16)}$ and also in the line of basic relationships of fracture toughness with the morphological nature affecting the flow characteristics of a matrix. An increase in susceptibility to plastic flow with a decrease in tensile strength enhances the fracture toughness of a matrix, ${ }^{16,19)}$ which may be the primary reason that ultimately governed the fracture toughness of the weld in present investigation.

\section{Conclusions}

A variation in welding energy input affects the hardness, tensile properties, fatigue crack growth rate $(d a / d N)$ characteristics and fracture toughness $\left(K_{\mathrm{Q}}\right)$ of multipass flux cored submerged arc weld primarily due to its influence on morphology of the weld consists of different amount of coarse and fine dendrites and coarse and fine reheat refined grains. The increase in energy input reduces the hardness, ultimate tensile strength and yield strength but enhances the ductility and $K_{\mathrm{Q}}$ of the weld. However, the increase in energy input has been found to reduce the $d a / d N$ at higher $\Delta K$ of the order of $45 \mathrm{MPa} \sqrt{\mathrm{m}}$ but to enhance the same more significantly with the lowering of $\Delta K$ to 30 and $15 \mathrm{MPa} \sqrt{\mathrm{m}}$. The $K_{\mathrm{Q}}$ and $d a / d N$ of the weld are found to be well correlated with its tensile strength, where an increase in tensile strength reduces the $K_{\mathrm{Q}}$ but enhances the $d a / d N$ at $\Delta K$ 
higher than $30 \mathrm{MPa} \sqrt{\mathrm{m}}$.

\section{REFERENCES}

1) P. T. Oldland, C. W. Ramsay, D. K. Matlock and D. L. Olson: Weld. J., 68 (1989), No. 3, 158-s.

2) J. A. Gianetto, N. J. Smith, J. T. McGratt and J. T. Bowker: Weld. J., 71 (1992), No. 11, 407-s.

3) F. Matsuda, Z. Li, P. Bernasovsky, K. Ishihara and H. Okada: Weld. World, 29 (1991), No. 9/10, 307.

4) P. Youngyuth, P. K. Ghosh, P. C. Gupta, A. K. Patwardhan and Satya Prakash: Int. J. Join. Mater., 5 (1993), No. 5, 31.

5) P. Youngyuth, P. K. Ghosh, P. C. Gupta, A. K. Patwardhan and Satya Prakash: Mater. Trans. JIM, 34 (1993), No. 6, 533.

6) P. Yongyuth, P. K. Ghosh, P. C. Gupta, A. K. Patwardhan and Satya Prakash: Int. J. Join. Mater., 7 (1995), No. 2/3, 87

7) P. K. Ghosh, P. Nagesh Babu and P. C. Gupta: ISIJ Inl., 34 (1994), No. 3, 280.

8) T. Kunio and K. Yamada: Microstructural Aspect of the Threshold Condition for Non Propagating Fatigue Cracks in Martensitic-ferritic Structure, ed. by Fong, Fatigue Mechanism, ASTM STP-675, (1979).

9) P. K. Ghosh, P. Youngyuth, P. C. Gupta, A. K. Patwardhan and Satya Prakash: ISIJ Int., 35 (1995), No. I, 63.

10) S. T. Rolfe and J. M. Barsom: Fracture and Fatigue Control in Structures, Prentice-Hall Inc., Englewood Cliffs, New Jersey, (1997).

11) G. M. Evans: Weld. J., 61 (1982), No. 4, 125-s.

12) G. M. Evans: Weld. J., 62 (1983), No. 11, 313-s.

13) K. K. Das, G. L. Datta and B. Sasmal: Proc. of Symp. on recent development in welding metallurgy and process, BARC, Bombay, (1985), 36

14) H. M. Hussain, P. K. Ghosh, P. C. Gupta and N. B. Potluri: Trans. Indian Inst. Met., $\mathbf{5 0}$ (1997), No. 4, 275.

15) H. M. Hussain, P. K. Ghosh, P. C. Gupta and N. B. Potluri: Weld. J., 75 (1996), No. 7, 209-s.

16) H. M. Hussain, P. K. Ghosh, P. C. Gupta and N. B. Potluri: Int. J. Join. Mater., Communicated, (1998).

17) R. W. Hertzberg: Deformation and fracture mechanics of engineering materials, 3rd ed., John Wiley \& Sons, New York, (1989), 530.

18) D. Radaj: Heat Effects of Welding, Springer-Verlag, Berlin, (1992), 9.

19) G. E. Dieter: Mechanical Metallurgy, 2nd ed., McGraw Hill Book Co., New York, (1976), 273. 